\title{
Analysis of sickness absence among employees of four NHS trusts
}

\author{
K A Ritchie, E B Macdonald, W H Gilmour, K J Murray
}

\begin{abstract}
Objectives-To determine the value of using routinely collected sickness absence data as part of a health needs assessment of healthcare workers.

Method-Sickness absence records of almost 12900 NHS staff for one calendar year were analysed. Three measures of absence, the absence rate, the absence frequency rate, and the mean duration of absence, were assessed for the population and comparisons made between men and women, full and part time and different occupational groups of staff. Also, the main causes of sickness absence were found.

Results-Almost $60 \%$ of the study population had no spells of sickness absence in the year of study and almost $20 \%$ had only one spell of sickness absence. Female staff were more likely to have experienced sickness absence than male staff. Although absence due to conditions related to pregnancy were included in the analysis, the incidence of these was not sufficient to account for the higher rates of absence among female staff. In general, full time staff had greater rates of sickness absence than part time staff. $71 \%$ of all absences were of $<1$ week duration. The main known causes of sickness absence were respiratory disorders, digestive disorders, and musculoskeletal disorders.

Conclusions-The transition from units managed directly from the health board to trusts with individual responsibility for personnel issues at the time of data collection resulted in variations in the quality of data available for analysis. This together with the use of "dump" codes has influenced the quality of the analysis. However, such data should be available for analysis to tailor occupational health care to the needs of the population.

(Occup Environ Med 1999;56:702-708)
\end{abstract}

University of Glasgow, Department of Public Health, Glasgow, UK

K A Ritchie

E B Macdonald

W H Gilmour

K J Murray

Correspondence to:

Dr K A Ritchie, University of

Glasgow, Department of

Public Health, 1 Lilybank

Gardens, Glasgow G12 8RZ,

UK. Telephone 0141330

4038; fax 01413305018 .

Accepted 14 June 1999

Keywords: healthcare workers; sickness absence; absence

Losses in the NHS resulting from staff absence due to sickness are known to be substantial. Of the NHS resources $70 \%$ are spent on employing staff ${ }^{1}$ and rates as high as $6 \%$ of all working days lost due to sickness absence have been reported among NHS staff in Scotland. ${ }^{2}$ It has previously been found that management of sickness absence within the NHS is important for economic reasons. ${ }^{3}$. Also, as occupational health is becoming increasingly recognised in many NHS trusts, analysis of data on sickness absence permits monitoring the health of employees and identifies those who might benefit from appropriate interventions to improve personal health. ${ }^{45}$ The main concerns of healthcare workers about their health have included musculoskeletal disorders ${ }^{6-8}$ and risk of infection. ${ }^{9-11}$ By undertaking systematic analysis of sickness absence data the basis of these concerns can be ascertained.

Although many studies of sickness absence have been conducted among healthcare personnel, most of these have concentrated on only one group of staff. ${ }^{12-15}$ The limitations of these studies arise from the diversity of occupations, ages, and hours of work among hospital staff, which result in very complex analyses. ${ }^{12} 1617$ However, these analyses are of value to both occupational health departments and management as part of health needs assessment allowing appropriate development of both policies for absenteeism and occupational healthcare services for all healthcare workers.

As part of an extensive project designed to identify the healthcare needs of healthcare workers, an analysis was performed of routinely collected sickness absence data of the staff of acute hospitals and one community service in Lanarkshire in Central Scotland. This took place during a period of transition from units managed directly by a health board to trusts and rapid expansion of occupational health services for those employees included in the study. The data described below were collected routinely by the personnel departments of the trusts included in the study.

\section{Method}

The sickness absence records of all employees of the four trusts in Lanarkshire who were employed during the calendar year 1993 were obtained from the personnel and manpower information system (PMIS) on which they
Table 1 Number of staff in the population by occupational group

PAMS=professions allied to medicine.

\begin{tabular}{lrrrr}
\hline & $\begin{array}{c}\text { Women } \\
\text { part time }\end{array}$ & $\begin{array}{c}\text { Women } \\
\text { full time }\end{array}$ & $\begin{array}{l}\text { Men } \\
\text { part time }\end{array}$ & $\begin{array}{l}\text { Men } \\
\text { full time }\end{array}$ \\
\hline Ancillary & 1551 & 117 & 164 & 144 \\
Maintenance & 0 & 0 & 1 & 199 \\
Administration & & & & \\
$\quad$ and clerical & 592 & 1000 & 29 & 204 \\
Nursing & 2988 & 3128 & 83 & 625 \\
PAMS & 168 & 346 & 1 & 57 \\
Labs and estates & 102 & 147 & 3 & 182 \\
Pharmacists & 5 & 34 & 0 & 19 \\
Medical and & & & & \\
$\quad$ dental & 79 & 329 & 72 & 509 \\
Total & 5485 & 5101 & 353 & 1939 \\
\hline
\end{tabular}


Table 2 Spells of absences (n (\%)) of women and men, part time and full time staff

\begin{tabular}{lcccc}
\hline No of spells & Women part time & Women full time & Men part time & Men full time \\
\hline 0 & $3041(55.4)$ & $2905(57.0)$ & $280(79.3)$ & $1369(70.6)$ \\
1 & $1174(21.4)$ & $1015(19.9)$ & $29(8.2)$ & $296(15.3)$ \\
2 & $704(12.8)$ & $613(12.0)$ & $15(4.3)$ & $154(7.9)$ \\
3 & $303(5.5)$ & $303(5.9)$ & $17(4.8)$ & $70(3.6)$ \\
4 & $156(2.8)$ & $138(2.7)$ & $7(2.0)$ & $22(1.1)$ \\
5 & $64(1.2)$ & $63(1.2)$ & $4(1.1)$ & $9(0.5)$ \\
$\geqslant 6$ & $43(0.8)$ & $64(1.3)$ & $1(0.3)$ & $83(1.0)$ \\
Total & $5485(100)$ & $5101(100)$ & $353(100)$ & $1939(100)$ \\
\hline
\end{tabular}

were electronically stored. This study population consisted of around 12900 NHS staff and included all occupational groups. The PMIS consisted of four files, one for each of the following: current staff, leavers, absence, and accidents. The staff and leavers files contained personal details of employees including sex, date of birth, current grade, etc. The absence file included all staff absences from all causes - such as annual leave, statutory days, sickness absence, study leave, etc. The study reported here was solely concerned with absence attributable and recorded as due to sickness and from this point will be referred to as absence. Periods of absence, for whatever cause, were compiled for a ward or department on to an absence return form by the ward manager and this was submitted, weekly, to the personnel department. Absences were then entered into the computerised system by a clerk in the personnel department. Each spell of sickness absence of between 3 and 5 days was required to be self certified by the staff member, and absences of $>5$ days duration required a medical certificate. Absences of 1 or 2 days could be uncertified by the staff member, although a reason for a period of absence was included by the line manager in the weekly absence return. Coding of cause of absence was carried out by the clerk from a predetermined classification system provided by the occupational health service.
The accident file contained information on all recorded workplace accidents involving staff members. The data contained in this file has not been included in any of the analyses reported in this paper.

The files relating to the year of study were captured from the PMIS system and transferred to a personal computer. To preserve confidentiality employee names were omitted although individual staff numbers were retained to allow merging with other files. Staff files were merged with absence files and unwanted data were removed. The resulting records contained personal details including the employees' age, sex, Whitley category, whether full time or part time and contracted hours of work as well as the dates and cause of each spell of absence. After the process of merging the staff files with the absence files, it was apparent that there were inconsistencies in the data. Some episodes of sickness absence had been entered more than once in the original PMIS computer system. To remove multiple entries of the same period of sickness absence, short programmes were written using SPSS to identify duplicate records and eliminate these duplicates. Duplicates were identified as such by the dates of the start and end of the period of absence. Other inconsistencies noted in the data were discrepancies in the start and end dates of absence and the associated number of days duration recorded. In this instance the number of days of absence was taken as the measure of duration of each spell as it was assumed that the effect of shift patterns may have resulted in these discrepancies in the date recordings and total days absent.

In the United Kingdom NHS the pay structure and conditions of service are based on agreements made in the National Whitley Council. Hence occupational groups within

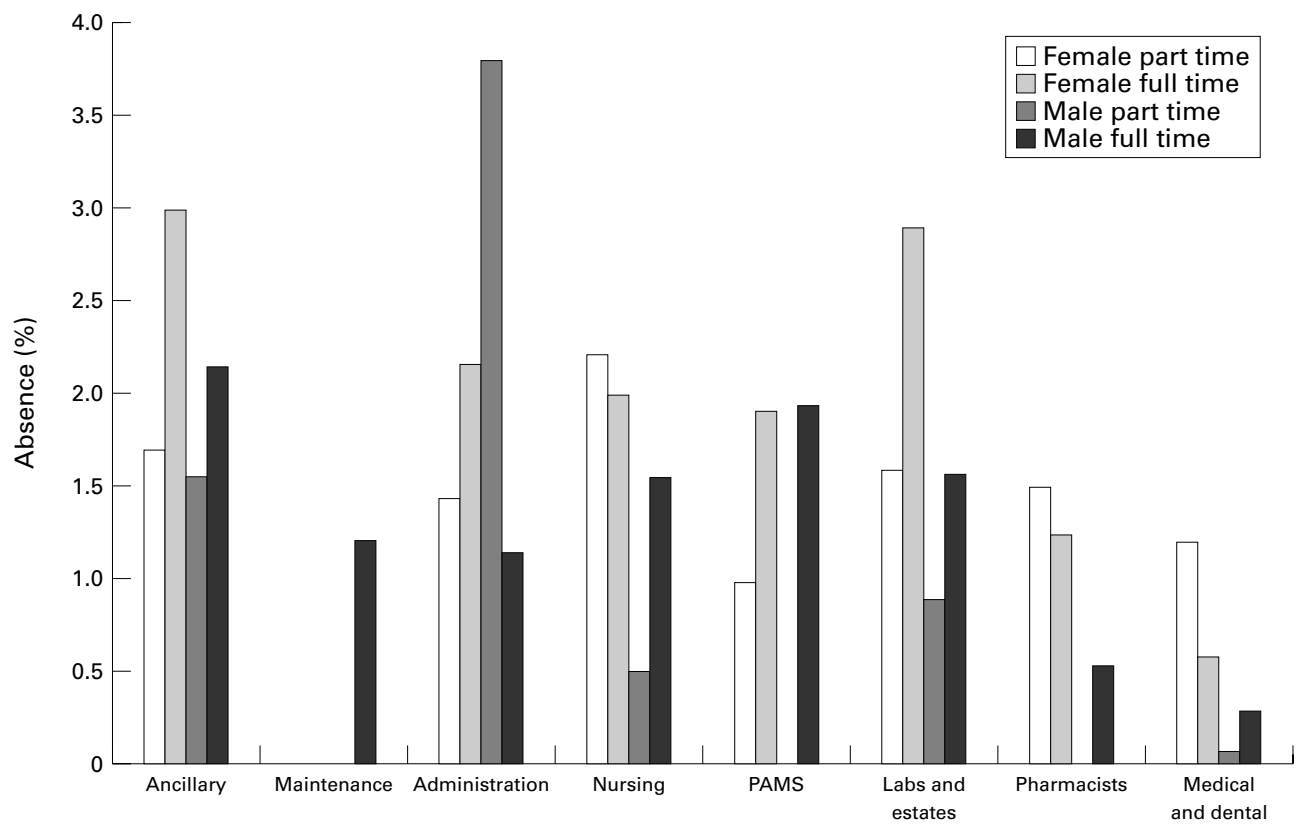

Figure 1 Age standardised absence rates. One long spell of absence among the very few part time male administrative staff has resulted in an apparently high rate of absence. 


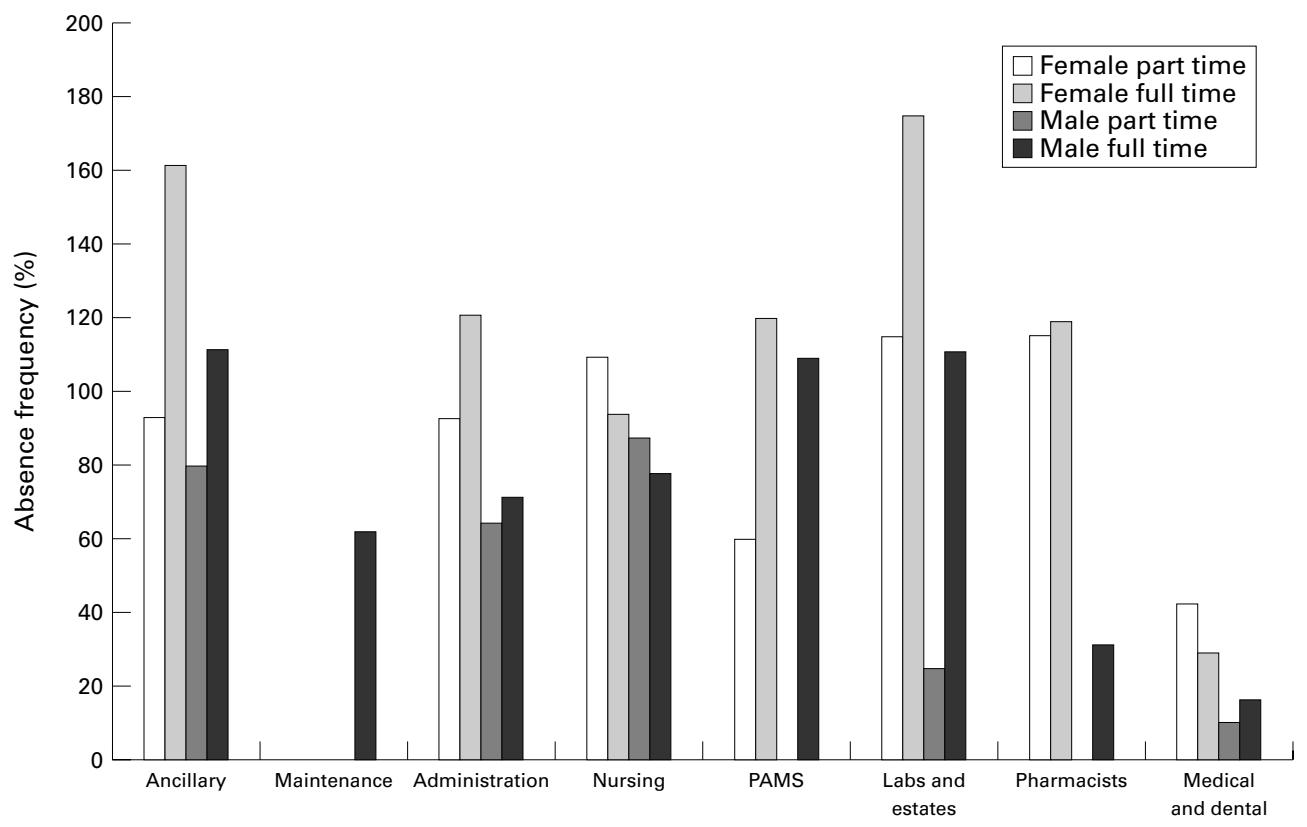

Figure 2 Age standardised absence frequency rate by occupational group.

the NHS are grouped by Whitley category. There are 15 Whitley categories determined by staff grade, however, some occupational groups - for example, medical staff-are covered by more than one Whitley category. For the purposes of this study Whitley categories were combined for grades of similar occupational grouping. This resulted in eight different occupational groupings being used in the analysis described here: medical and dental; pharmacists; laboratory and estates; nursing; administrative and clerical; maintenance; ancillary; and professions allied to medicine, which include physiotherapists, occupational therapists, radiographers, dieticians, and other such professions.

Employees contracted to work for $<2$ hours a week (generally nursing bank staff) and those who had been employed for $<10$ days during

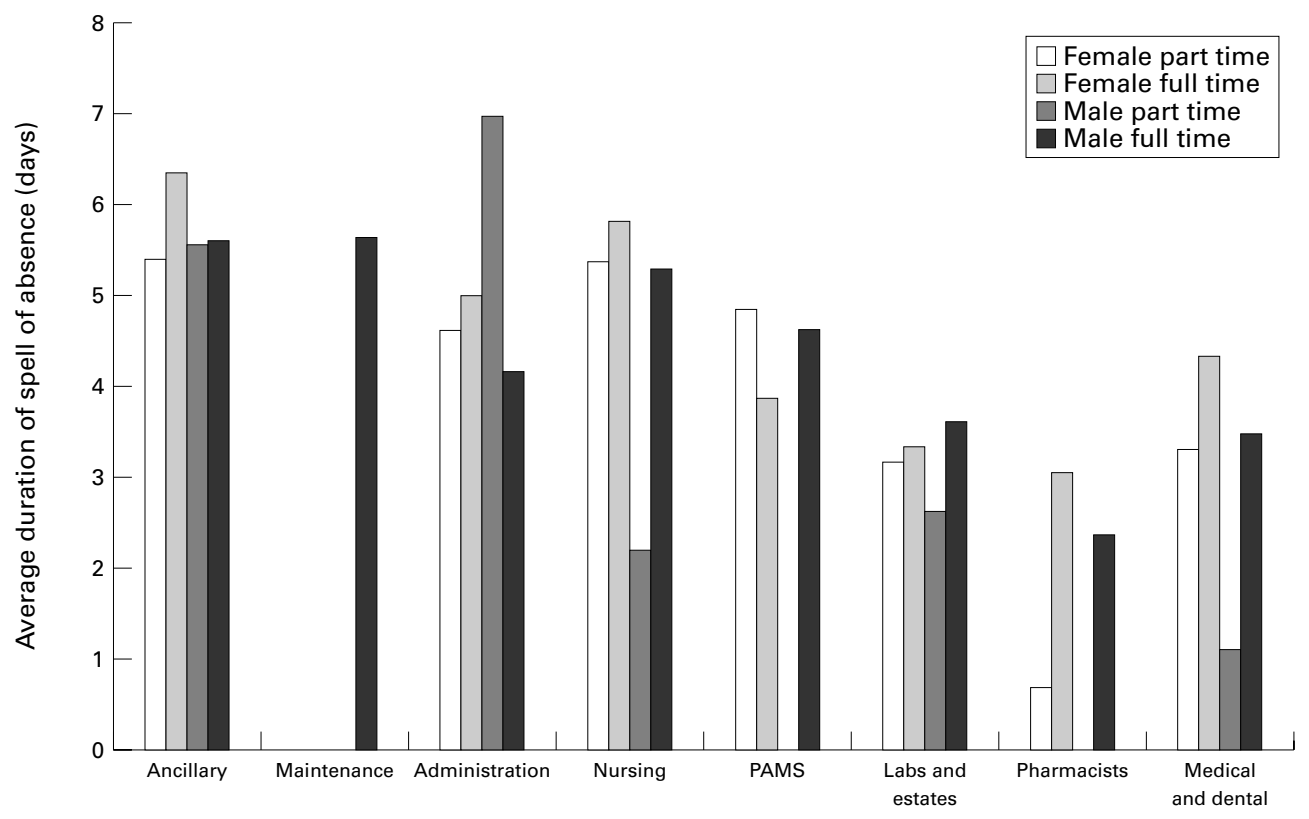

the year in question were excluded from the analysis. Also, those staff whose Whitley category was missing from the data were also excluded. In total, 10492 episodes of absence among 12878 staff were subsequently analysed.

The distinction between full time and part time workers, in terms of hours worked, proved to be obscure. Some workers, categorised as full time, were contracted to work only 3 hours a week whereas other full time workers worked 40 hours a week, 37.5 hours being the median number worked each week. By contrast, part time staff were recorded as working between 3 and 38.5 hours with 20 hours being the median worked a week. Careful consideration was given to reclassifying workers by the number of hours worked. However, as only $3.2 \%$ of those described as part time worked $\geqslant 35$ hours a

Figure 3 Age standardised average duration per spell of absence by occupational group. 


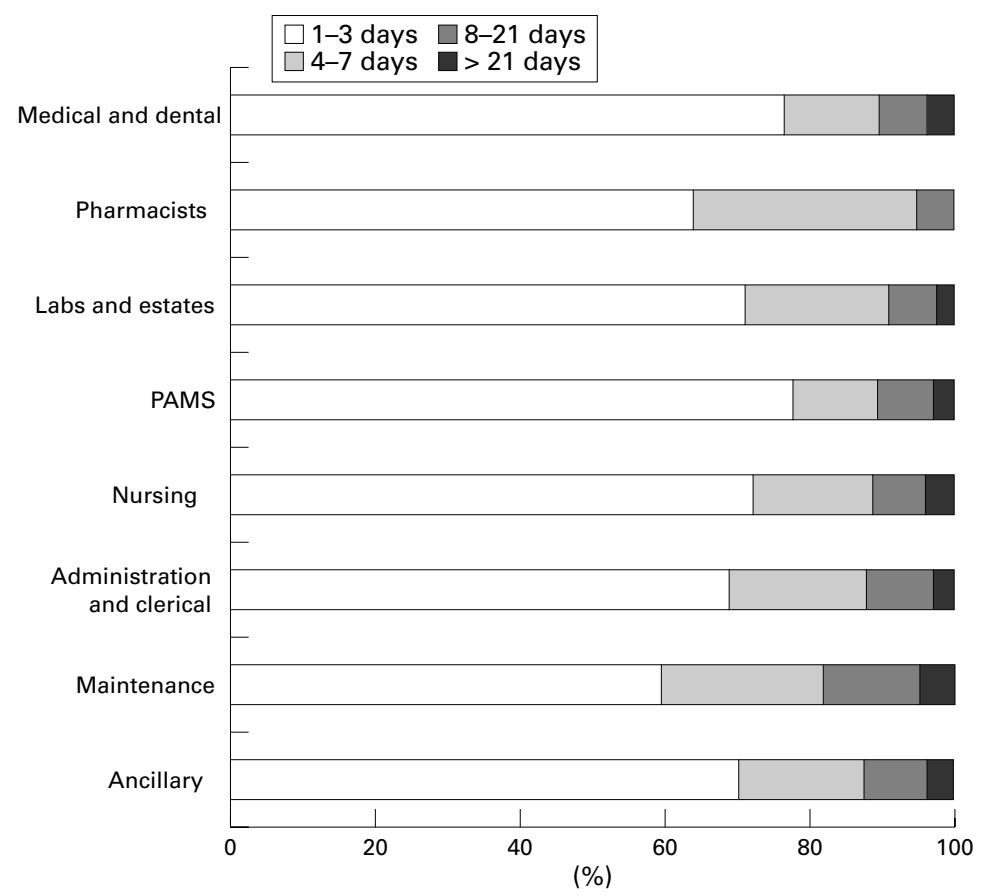

Figure 4 Distribution of duration of spells of absence by occupational group.

week and $<0.5 \%$ of full time staff were recorded as working $<35$ hours a week it was ultimately decided to use the formal classification included in the PMIS system.

Three measures of absence were calculated in this study - an overall absence rate, an absence frequency rate, and a measure of average duration of spells of absence. The following definitions have been derived from those used by Seccombe. ${ }^{18}$ where the absence rate can be defined as:

total duration of all spells of absence during period $\times 100 \%$

total contracted time during that period

The contracted time was calculated assuming a working year of 225 days. ${ }^{18}$ The percentage of the working year that each staff member had been in employment was also incorporated into the equation. The total number of possible working days was divided by 225 to give the measure termed "staff year".

The equation used to calculate the absence rate for any subgroup was therefore:

total number of days of absence

$\frac{\text { in } 1993}{\text { total number of staff years } \times 255} \times 100 \%$

The absence frequency rate for any subgroup is defined by:

$\frac{\text { total number of spells of absence }}{\text { mean number of staff }} \times 100 \%$

As this study was carried out over a 1 year period, this is equivalent to:

$$
\frac{\text { total number of spells of absence }}{\text { total number of staff years }} \times 100 \%
$$

For each person with at least one absence during the year, the mean duration of absence per spell is defined as:

$$
\begin{array}{r}
\text { total duration of all spells of absence } \\
\text { during the period }
\end{array}
$$

To obtain the mean duration for any subgroup, the values for the people in the subgroup who had at least one absence during the year were averaged.

Spells of absence included in these two equations were those which started during the year of study although they may not necessarily have been completed.

\section{Results}

Table 1 shows the occupational profile for the combined staff of the four trusts. For the purposes of this analysis men and women and full and part time staff were treated separately. Of the total study population $53 \%$ were nursing staff, $15 \%$ ancillary, $14 \%$ administrative and clerical staff, and almost $8 \%$ medical and dental staff. In all, $82 \%$ of the population were women and these comprised almost equal numbers of full and part time staff. Only 353 men, representing $2.7 \%$ of the total population, were part time.

Table 2 shows the distribution of the number of spells of sickness absence experienced by the study population in 1993 .

Of the population $59 \%$ had no spells of recorded sickness absence in 1993 and nearly $20 \%$ had only one spell of absence. Female staff were more likely to have experienced absence than male staff, and almost $44 \%$ of women had one or more periods of absence compared with $28 \%$ of male staff. The greatest number of spells of absence was 17 with two people having 17 spells of absence attributed to sickness. Comparison of staff with only one

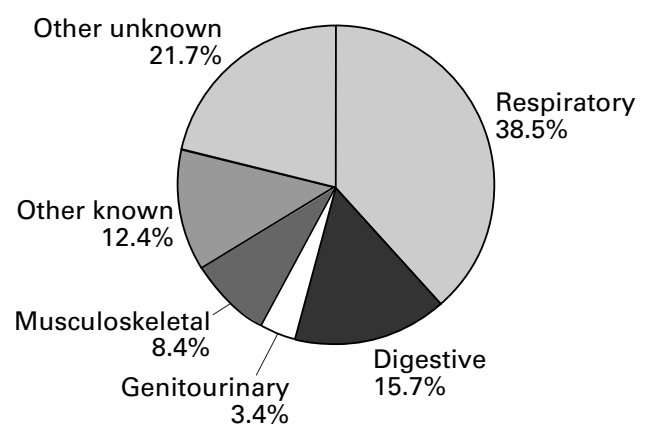

Figure 5 Causes of spells of absence.

Table 3 Relation between causes of spells of absence and medical confirmation of illness

\begin{tabular}{llll}
\hline & $\begin{array}{l}\text { Unconfirmed } \\
(\%)\end{array}$ & $\begin{array}{l}\text { Self } \\
\text { confirmed } \\
(\%)\end{array}$ & $\begin{array}{l}\text { Medically } \\
\text { confirmed } \\
(\%)\end{array}$ \\
\hline Respiratory disorders & 67.4 & 19.9 & 12.7 \\
$\begin{array}{l}\text { Digestive disorders } \\
\text { Genitourinary disorders }\end{array}$ & 84.9 & 8.2 & 6.9 \\
$\begin{array}{l}\text { Musculoskeletal } \\
\text { disorders }\end{array}$ & 38.8 & 13.9 & 45.1 \\
$\begin{array}{l}\text { Other known causes } \\
\text { Other unknown causes }\end{array}$ & 41.9 & 15.7 & 45.6 \\
\hline
\end{tabular}




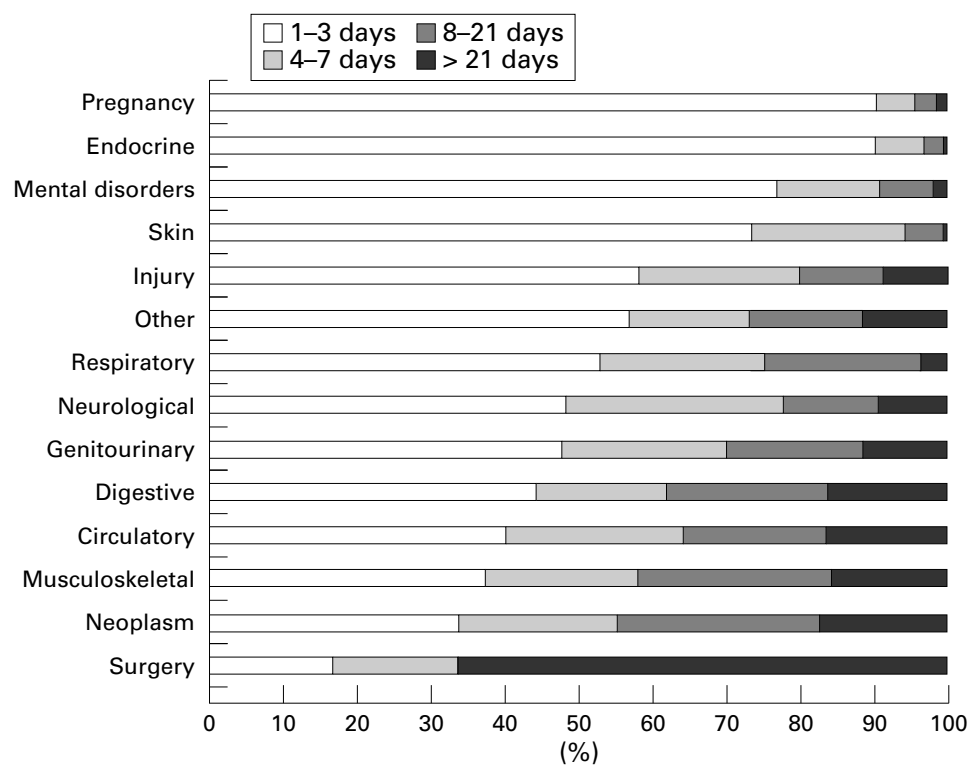

Figure 6 Distribution of durations of spells of absence by cause.

spell of absence with those with more than one spell showed similar demographic profiles and no differences in cause of absence.

The overall rate of sickness absence was found to be 4.02 days absence per staff year. Crude absence rates were age standardised by the indirect method with the age distributions for each of the subgroups considered separately. ${ }^{19}$ Results are shown in figure 1. Male staff had lower rates of absence than female staff. For most occupational groups, full time staff had greater rates of sickness absence than part time staff. However, the rates for full time and part time nursing staff were very similar. Among medical and dental and pharmacy staff, full time staff also showed a lower rate of absence. Medical and dental staff had by far the lowest rate of recorded sickness absence.

The frequency of absence was calculated for each of the groups and then age standardised to give the results as shown in figure 2 . Frequency of absence of the different occupational groups of staff shows a similar pattern to absence rates. Male staff were absent due to sickness less often than female staff and part time staff in general had fewer spells of absence than full time staff. Medical and dental staff had the lowest frequency rates.

The variation in duration per spell of absence for those people with at least one absence during the study year was compared among the different occupational groups. Figure 3 shows that for all groups, except women in the professions allied to medicine and male administrative staff, the mean dura- tion per spell of absence was shorter for part time than full time staff. One very long spell of absence by a male administrative worker resulted in a disproportionately high mean. The shortest mean duration per spell was among the laboratory and estates and pharmacy staff. The longest mean duration per spell was experienced by the ancillary staff.

The distribution of duration of spells of absence by occupational group is shown in figure 4 . Most of the absences among all occupational groups are short term absences of $<1$ week. Maintenance staff had proportionately the greatest number of absences of $>1$ week and pharmacy staff had the fewest of these longer term absences.

Figures 3 and 4 show the skewed nature of the data analysed in this study. Although $>71 \%$ of all absences were $\leqslant 3$ days, a few absences were of long duration. This resulted in a mean duration per spell of 5.3 days.

\section{CAUSES OF ABSENCE}

All records of sickness absence included a cause of absence which was categorised into one of 25 main reasons for illness. Unfortunately, almost $22 \%$ of absences were coded as other during this process. For the purposes of the following analysis these 25 categories were further grouped into 14 causes of absence derived from international classification of diseases chapter headings with an additional grouping for those absences where the cause was described as surgery in the original data. Figure 5 shows the distribution of the main causes of absence. Causes which individually accounted for $<2.5 \%$ of all spells of absence have been grouped together as "other known" in this figure. The main known causes of absence were respiratory disorders, digestive disorders, and musculoskeletal disorders.

Table 3 shows the relation between cause of spells of absence and certification of those spells.

Figure 6 shows the association between cause of absence and duration of spell. It can be seen that digestive, neurological, and other causes are associated with relatively short spells of absence, whereas neoplasms are associated with long spells of absence. Table 2 and figure 6 show that duration of spell of absence and cause are related with those causes resulting in short spells of absence, for example, respiratory and digestive disorders are generally uncertified absences whereas medically certified absences include spells from, for example, musculoskeletal disorders.

Table 4 shows the reasons for spells of sickness absence among the occupational groups.

Table 4 Reasons for sickness absence by occupational group

\begin{tabular}{llllrrrr}
\hline & Respiratory & Digestive & Genitourinary & Musculoskeletal & \multicolumn{1}{l}{$\begin{array}{l}\text { Other } \\
\text { known }\end{array}$} & $\begin{array}{l}\text { Other } \\
\text { unknown }\end{array}$ & total \\
\hline Ancillary & 28.2 & 23.3 & 3.0 & 10.7 & 8.7 & 26.2 & 100.0 \\
Maintenance & 39.4 & 16.3 & 0.0 & 11.5 & 12.5 & 20.2 & 100.0 \\
Administration and clerical & 41.7 & 18.7 & 4.7 & 4.2 & 12.4 & 18.3 & 100.0 \\
Nursing & 38.6 & 12.9 & 5.8 & 9.4 & 10.6 & 22.6 & 100.0 \\
PAMS & 46.6 & 20.7 & 6.8 & 4.7 & 9.6 & 11.5 & 100.0 \\
Laboratories and estates & 50.9 & 16.6 & 3.1 & 6.2 & 10.8 & 12.4 & 100.0 \\
Pharmacists & 25.0 & 5.6 & 2.8 & 5.6 & 8.8 & 8.3 & 100.0 \\
Medical and dental & 33.8 & 5.7 & 0.6 & & & 44.6 & 100.0 \\
\hline
\end{tabular}


There was some variation in the pattern of causes of absence between different occupational groups. Professions allied to medicine and ancillary staff were found to have a greater number of spells of absence resulting from digestive disorders and over half of all of the absence experienced by laboratory and estate workers was the result of respiratory disorders. Of all spells of absence of medical and dental staff $45 \%$ were coded as caused by other reasons. Musculoskeletal disorders accounted for between $4.2 \%$ and $11.5 \%$ of absences when occupational groups were compared. Maintenance workers had the highest number of spells of absence due to this cause. Of spells of absence among nursing staff $9.4 \%$ resulted from musculoskeletal problems, just over the mean $(8.4 \%)$ for the total population.

\section{Discussion}

One consequence of the continuing development of computing technology is that it is now possible to access large collections of routinely collected data stored electronically by institutions, and to manipulate these so as to allow for health based analyses to be carried out. In this study, information held separately by personnel departments and payroll sections were matched together to allow for some insight into the characteristics of sickness absence of healthcare employees.

The accuracy of the data obtained from the PMIS was of some concern. Intensive data cleaning was required before undertaking any analyses. Manipulation of the data from a computer system based on information relating to individual people to a population based format highlighted errors and inconsistencies in the data that might otherwise have remained hidden. For example, many duplications of spells of absence were found, inconsistencies in the numbers of days sick when compared with the dates of absence, and instances when sickness absence was attributed to other causes.

Analysing patterns of absence among a population of healthcare workers is complex for several reasons. Firstly, examination of the sociodemographic characteristics of the population shows that it is heterogeneous, precluding generalisation of any results to the whole population. For example, both sexes are represented, yet whereas about half the female workers are part time, the smaller number of men in the population work predominantly full time. Also, the population comprises a diverse range of occupational groups which range from social class 1 represented by doctors and dentists, to social class 4 , represented by porters, and manual workers.

Of particular note is that of this population almost $60 \%$ of employees had no recorded absence during the year of study and a further $20 \%$ had only one spell of absence. This is comparable with the findings among one of the district health authorities in the study of McKeown and Furness. ${ }^{17}$ Female staff had higher absence rates than male staff for all occupational groups except the part time administrative staff, in which one man had a very long period of absence which raised the rate among a small group. Also, full time men in the professions allied to medicine had a very slightly higher absence rate than their female equivalents.

A higher rate of sickness absence among female staff than male staff has been noted by several authors. ${ }^{61721}$ The inclusion of absence as a result of pregnancy cannot account for this higher rate among female staff as the number of spells and the total number of days absence due to conditions related to pregnancy are small compared with the total recorded absence. A previous study ${ }^{20}$ suggested that differences in absence rates between men and women are removed by standardisation of age and occupational status. This is not apparent in our study.

Ancillary staff were found to have the highest rates of absence and the longest duration of periods of absence. Laboratory and estate staff had the greatest number of spells of absence but the shortest mean duration of absence. Medical and dental staff were found to have the lowest rates of absence and the lowest number of spells of absence. These results reflect findings from previous studies with rates of absence being related to socioeconomic status. ${ }^{22}$

Previous studies have also suggested that there is underreporting of absence among the medical profession ${ }^{23}$ and this may be reflected in our results. Although medical and dental staff had fewer spells of absence the mean duration of spells of absence was similar to other occupational groups. However, they had relatively fewer spells of absence for respiratory and digestive disorders, and $45 \%$ of absence was classified as unknown. This may reflect that they are less likely to be absent for spurious reasons and also may be reluctant to accurately describe causes of absence when they take time off work due to sickness. Alternatively the diagnoses which they describe on certificates may be more difficult for the clerks to classify.

Among most of the occupational groups, part time staff had lower rates of absence than full time staff. The absence frequency rate was lower for most groups of part time workers although there was much less variation among the mean duration per spell of absence. Previous reports in the literature are conflicting in the absence experience of full and part time hospital staff with some studies finding absence rates in full time staff higher, some finding higher rates in part time staff, and some finding no difference in rates. ${ }^{16}{ }^{17}$ The reasons for these variations in results are unclear.

Overall, $71 \%$ of spells of absences were of $\leqslant 3$ days and only $11.8 \%$ of spells of absence lasted $>7$ days. Maintenance staff had the highest number of longer spells of absence ( $\geqslant 8$ days) and pharmacists had the lowest. Comparisons with other studies on the duration of spells of absence is not straightforward as different authors define short and long term absence differently. However, the proportion of short spells of absence would seem to be more than that found by McKeown and Furness ${ }^{17}$ but less than the proportions found in the study of Al-Shammari et al of hospital staff in Saudi Arabia. $^{6}$ 
The main known causes of absence were respiratory disorders, digestive disorders, and musculoskeletal disorders. A major failing in the data available for analysis in this study was the high proportion of absences which were classified in PMIS as of other causes. In total these amounted to over a fifth of all recorded absence. Most of these absences $(70.6 \%)$ were uncertificated, however uncertificated absence does not preclude a cause of absence being recorded as $85 \%$ of digestive disorders and neurological disorders and $67 \%$ of respiratory disorders were also recorded as uncertificated. It was interesting how little of the absence was attributable to pregnancy and gynaecological reasons. Their impact on absence even in largely female dominated populations was not sufficient to account for the sex differences in rates of sickness absence.

The data provide some useful information as part of the health needs assessment of healthcare workers. In this study, maintenance staff were found to have the greatest number of spells of absence of $>1$ week and more musculoskeletal absence than nurses. Among this population of healthcare workers considerable efforts had been undertaken by the occupational health service to reduce manual handling injury in nurses by ergonomic improvements and manual handling training and there has been less focus on the related needs of maintenance staff. This study highlights the musculoskeletal needs of this group and their need for new interventions. The high proportion of absence due to digestive disorders in professions allied to medicine and ancillary workers is of concern as this group includes food handlers and indicates the need for further scrutiny of their morbidity. This may, however, indicate appropriate behaviour in food handlers with diarrhoeal disorders. The relatively high prevalence of respiratory disorders in laboratory and estate workers could reflect occupational problems due to the mixed exposures of estate staff and the different chemical and biological exposures of laboratory workers. Sickness absence is a crude indicator and where there are systematic occupational differences then further targeted investigative work would be required to determine the evidence base for these differences to develop targeted programmes.

It is recognised that several factors contribute to the patterns of absence in different groups of staff. ${ }^{15}$ It is also accepted that an occupational health service should be aware of the main causes of morbidity of groups of staff both by work location and by occupation. ${ }^{24}$ The data presented here do not show clear associations between, for example, rates of absence and socioeconomic groupings and other studies of this kind have referred to limitations relating to the data available for analysis. ${ }^{3}$ In this study, the changes in management structure at the time of data collection and use of "dump" codes may have influenced the quality of data collection.

Although the study did not identify large differences in morbidity between occupational groups, it does confirm the value of routine monitoring of sickness absence data to identify significant variations in illness behaviour and causes of morbidity for those involved in the occupational health care of populations.

1 Seccombe I, Turner A. Measuring and monitoring sickness absence in the NHS. A practical guide. Oxford: Health Eduabsence in the NHS. A pract

2 Absence in the NHS in Scotland. Scottish Health Management Efficiency Group. Edinburgh: SHMEG 1993. (Action Plan 29:2.)

3 Wright ME. Long-term sickness absence in an NHS teaching hospital. Occup Med 1997;47:401-6.

4 Harrington JM. The health of health care workers. $f \mathrm{R}$ Coll Physicians Lond 1990;24:189-95.

5 Baxter PJ. Research in Occupational Health. The UK National Health Service. Fournal of Society of Occupational Medicine 1991;41:7-9.

6 Al-Shammari SA, Bamgboye EA, Olubuyide IO. Sickness absenteeism among employees of a teaching hospital in Saudi Arabia. F R Soc Health 1994;114:6-10.

7 Larese F, Fiorito A. Musculoskeletal disorders in hospital nurses: a comparison between two hospitals. Ergonomics 994:37:1205-11.

8 Fuortes LJ, Shi Y, Zhang M, et al. Epidemiology of back injury in university hospital nurses form review of workers' compensation rexords and a case-control survey. F Occup Med 1994;36:1002-26.

9 Farsides CCS. HIV infection and health care workers. Care of the Critically Ill 1995;11:153-5.

10 DiBenedetto DV. Occupational hazards of the health care industry: protecting health care workers. American Association of Occupational Health Nurses fournal 1995;43:131-7.

11 Slagle DC, McNicol LB, Chavez JM. The epidemiology of sharps injuries and splash exposures at a military medical center. Mil Med 1994;159:302-7.

12 Fagin L, Carson J, Leary J, et al. Stress, coping and burnout in mental health nurses: findings from three research studies. Int $\mathcal{F}$ Soc Psychiatry 1996;42:102-11.

13 Smedley J, Egger P, Cooper C, et al. Manual handling activities and risk of low back pain in nurses. Occup Environ Med 1995;52:160-3.

14 Seccombe I, Buchan J. Absent nurses: the costs and consequences. Brighton, UK: Institute of Manpower Studies, 1993;250:1.

15 Balarajan R. Inequalities in health within the health sector. $B M \mathcal{A} 1989 ; 299: 822-5$.

16 Brown IM. Hospital staff sickness absence. Hospital 1968;March:94-7.

17 McKeown KD, Furness JA. Sickness absence patterns of 5000 NHS staff employed within Northallerton and South West Durham Health authorities. Fournal of Society of Occupational Medicine 1987;37:111-6.

18 Seccombe I. Measuring and monitoring absence from work. Brighton, UK. The Institute for Employment Studies, 1995: 1 .

19 Taylor PJ. International Labor Organisation encyclopaedia of occupational health and safety, 2nd ed. New York: ILO, 1983; $8-10$.

20 Sharp C, Watt S. A study of absence rates in male and female employees working in occupations of equal status. Occup Med 1995;45:131-6.

21 Pines A, Skulkeo K, Pollak E, et al. Rates of sickness absenteeism among employees of a modern hospital: the role of demographic and occupational factors. Br F Ind Med 1985; 42:326-35.

22 North F, Syme SL, Feeney A, et al. Explaining socioeconomic differences in sickness absence: the Whitehall II study. BMF 1993;306:361-6.

23 Smith M S, Sickness absence in male Royal Naval medical and dental branch ratings: 1981-9. Occup Med 1995, 45:40-4.

24 Macdonald E B, Audit and quality in occupational health Occup Med 1992;42:7-11. 